Article

\title{
Percutaneous Endoscopic Gastrostomy and
} Nutritional Interventions by the Pediatric Nutritional Support Team Improve the Nutritional Status of Neurologically Impaired Children

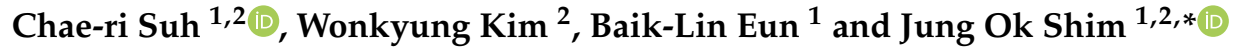 \\ 1 Department of Pediatrics, Korea University College of Medicine, Korea University Guro Hospital 1, \\ Seoul 08308, Korea; ch2307@naver.com (C.-r.S.); bleun@korea.ac.kr (B.-L.E.) \\ 2 Pediatric Nutritional Support Team, Korea University Guro Hospital, Seoul 08308, Korea; osim17@naver.com \\ * Correspondence: shimjo@korea.ac.kr; Tel.: +82-2-2626-3157
}

Received: 4 September 2020; Accepted: 10 October 2020; Published: 14 October 2020

\begin{abstract}
Aim: To evaluate the long-term effects of nutritional improvement following percutaneous endoscopic gastrostomy (PEG) tube feeding stratified by previous feeding method and to assess the impact of underlying muscle tone on the outcomes of the nutritional intervention. Methods: Neurologically impaired children who underwent PEG tube insertion and nutritional intervention provided by a pediatric nutritional support team were enrolled. We measured anthropometric variables, laboratory parameters, and nutritional intake at baseline, 6 months after PEG insertion, and the last visit. We evaluated the percent ideal body weight (PIBW), body mass index (BMI)-for-age $z$-score, and percentiles and calculated the ratios of calorie intake compared to required requirement (CIR) and protein intake compared to recommended requirement (PIR). Results: The PIBW and BMI-for-age $z$-score improved during the first 6 months ( $p=0.003$ and $p=0.005$, respectively). The CIR $(p=0.015)$ and PIR $(p=0.004)$ increased during the study period. The baseline BMI and PIBW of the previous nasogastric tube feeding group were better than those of the oral feeding group ( $p=0.02$ and $p=0.03$, respectively). The BMI-for-age $z$-score, PIBW, CIR, and PIR improved in the hypertonic group ( $p=0.03,0.02,0.03$, and 0.01 , respectively). Conclusion: PEG tube feeding and active nutritional intervention improved the nutritional status of neurologically impaired children immediately after PEG insertion. The nutritional requirements might vary by the muscle tonicity.
\end{abstract}

Keywords: child; gastrostomy; growth; malnutrition; nutritional support

\section{Introduction}

With advances in medical treatments, the survival of neurologically impaired children has increased. However, along with improved life expectancy, feeding problems are on the rise [1]. Oropharyngeal dysfunction and gastroesophageal reflux are common problems in patients with severe impairments and can result in malnutrition and growth failure [2-6]. Malnutrition also decreases cerebral function; impairs immune function; leads to lean body mass, poor bone health, and micronutrient deficiencies; and diminishes respiratory muscle strength [7-9]. Severe malnutrition also leads to increased morbidity and mortality rates; however, $60 \%$ of patients are not evaluated for their feeding problems [3]. Thus, these disabilities lead to worsening of the individual's nutritional status, and subsequently, require specialized nutritional care to correct these problems. Pediatric patients, in particular, need professional and individualized nutritional care to treat complications and ensure proper growth and development. 
Percutaneous endoscopic gastrostomy (PEG) has long enabled enteral nutrition in children who are unable to meet their nutritional needs orally [10]. Since many clinicians consider PEG tube feeding as just another feeding route, most previous studies focused on complications of the procedure $[11,12]$ or compared the efficacies of different gastrostomy methods [13].

Nutritional intervention is important, particularly in children with moderate to severe protein-calorie malnutrition. The pediatric nutritional support team (PNST) is a multidisciplinary team consisting of physicians, including pediatric gastroenterologists, neonatologists, surgeons, dieticians, pharmacists, and nurses. A pediatric gastroenterologist coordinates the team as a leader, and the PNST evaluates the nutritional status of every patient who needs enteral or parenteral nutrition and/or any patient who needs special nutritional support under consultation and suggests future nutritional plans to attending doctors. Since there are few studies on the nutritional effect of PEG tube feeding on such patients, we sought to evaluate the ability of PEG tube feeding to improve nutritional status and assessed the efficacy of the regular nutritional intervention by PNST. We compared the nutritional status, including improvement in the anthropometric variables, in the oral feeding group and nasogastric (NG) tube feeding group according to the previous feeding method and muscle tonicity (hypertonic or hypotonic).

\section{Experimental Section}

\subsection{Study Enrollment}

This longitudinal retrospective cohort study was conducted at Korea University Guro Hospital (KUGH) and investigated the nutritional outcomes of PEG tube feeding in neurologically impaired children. The changes in the anthropometric parameters and nutritional status were measured before and after PEG feeding tube insertion. The KUGH Institutional Review Board approved this study (2019GR0354), and the requirement for informed consent was waived, due to the retrospective nature of the study.

Pediatric patients with neurological impairments who underwent PEG tube insertion between 2012 and 2018 at KUGH were eligible to participate. The exclusion criteria were (1) age $>20$ years, and (2) a short follow-up period ( $<6$ months). Each patient underwent at least three tests before PEG tube insertion, including a videofluoroscopy swallowing study, $24 \mathrm{~h}$ multichannel intraluminal impedance $\mathrm{pH}$ monitoring, and esophagogastroduodenoscopy (EGD), to assess the indications for PEG, in which a feeding tube was inserted using a pull-through or push-through technique.

\subsection{Assessment Schedule}

We analyzed the formatted medical records of the PNST at three time points: Immediately before PEG tube insertion (baseline), six months after PEG tube insertion (six months), and at the last hospital visit (last). The PNST evaluated the anthropometric parameters (height and weight) and laboratory tests (hemoglobin, lymphocytes, protein, albumin, total bilirubin, blood urea nitrogen, creatinine, calcium, and phosphorus) to check the nutritional status and general condition of the patients at every visit. The PNST calculated the patients' nutritional requirements (caloric and protein intake) and recommended an optimal nutritional plan if it was deemed insufficient. The PNST also recorded the following nutritional information: Anthropometric data, previously ingested food types, feeding route (oral, NG tube, or gastrostomy), the volume of food ingested daily, ingested calories and protein, laboratory tests, and recommended type and volume of the formula.

In real practice, the PNST routinely monitored all children in the intensive care unit, those who were receiving enteral nutrition or total parenteral nutrition, and those who were referred by their physicians. The PNST members gathered at least once a week and performed additional monitoring of patients if needed. The pediatric neurologists requested the PEG tube insertion or the PNST suggested tube insertion after the evaluation. 


\subsection{Anthropometric Evaluation and Nutritional Assessment}

The ulnar length was measured to predict the patients' height [14]. Bodyweight was measured using electronic weighing scales (the same scale at each visit). The height and weight were transformed to sex-specific $z$-scores of height-for-age, weight-for-age, body mass index (BMI)-for-age ( $\geq 24$ months of age), and weight-for-height ( $<24$ months of age) using the 2017 Korea National Growth Charts [15]. The growth curves for cerebral palsy (CP) according to sex and the Gross Motor Function Classification System (GMFCS) level [16] were used to evaluate the percentages of height-for-age, weight-for-age, and BMI-for-age and to calculate the percent of ideal bodyweight (PIBW). IBW was defined using the Moore method [17] and was used to calculate the PIBW or the ratio of IBW to the actual bodyweight.

In addition to gross motor function evaluation, the modified Ashworth scale (MAS) was used to evaluate the patients' muscle tone [18].

Malnutrition was assessed according to the range of BMI-for-age $z$-score divided by the World Health Organization growth standard as follows: Above 3, obese; above 2, overweight (overnutrition); above -2 , normal; between -2 and -3 , wasted (malnutrition); and below -3 , severely wasted (severe malnutrition) [19]. Waterlow's classification [20] was used as a reference evaluation for catch-up growth. Waterlow's classification defined mild malnutrition as $80 \%$ to $90 \%$ of the PIBW, moderate malnutrition as $70 \%$ to $80 \%$ of the PIBW, and severe malnutrition as less than $70 \%$ of the PIBW. The US Centers for Disease Control definition of weight status category was used to calculate the BMI-for-age percentile as follows [21]: Underweight, below the 5th percentile; normal, between the 5th and 85th percentile; overweight, between the 85th and 95th percentile; and obese, over the 95th percentile. With regard to the weight-for-height $z$-score, the nutritional status of children under 24 months old was assessed as wasted (weight-for-height $z$-score below -2), normal (between -2 and 2), or overweight (over 2) [15].

The PNST evaluated the current nutritional status and calculated the nutritional requirements based on anthropometric variables and laboratory test results. The nutrition level was divided into four stages by severity: Obese, well-nourished (overweight or normal), moderately malnourished (wasted), and severely malnourished (severely wasted) [20]. The nutritional status was evaluated by applying the standard bodyweight of neurologically impaired children. We defined children with a PIBW under $80 \%$, BMI-for-age percentile below the 5th percentile, and BMI-for-age $z$-score below -2 as the malnutrition group. The PNST recommended the amount of feeding formula based on the Schofield equation [22] and the protein requirement, as reported by Williams [23].

\subsection{Statistical Analysis}

The differences in data were examined using the Wilcoxon signed-rank test, and the differences between the oral feeding group and the NG tube feeding group were evaluated using the Mann-Whitney $U$ test. $p$-values $<0.05$ were considered statistically significant. Analyses were performed using SPSS 24.0 for Windows (SPSS Inc, Chicago, IL, USA).

\section{Results}

\subsection{Demographic Characteristics}

Thirty patients underwent PEG tube insertion during the study period, of whom 12 were excluded for the following reasons: Five children from secondary hospitals who came to our hospital for PEG insertion before returning to the secondary hospital following the procedure and seven children aged $>$ 20 years from the baseline. Table 1 demonstrates the nutritional characteristics of enrolled patients. Among the 18 included patients, 16 were older than 24 months, and two were younger than 24 months. Twelve were males, and six were females. The median age of the patients at baseline was 132.4 (interquartile range (IQR), 43.0-180.7) months, and the median intervention period was 50.4 (IQR, 33.9-71.8) months; the longest intervention period was 71.8 months. All children had intractable epilepsy and were bedridden. 
Table 1. Characteristics of the enrolled patients.

\begin{tabular}{cc}
\hline Characteristics & Number of Patients \\
\hline Male/female, $n$ & $12 / 6$ \\
Median age (months) (IQR) & $132.4(43.0-180.7)$ \\
Study duration of intermedius (months) (IQR) & $50.4(33.9-71.8)$ \\
Previous feeding & \\
Oral feeding, $n$ & 10 \\
NG tube feeding, $n$ & \\
Indications for PEG tube insertion & $8(5 / 3)$ \\
Aspiration (oral/NG tube), $n$ & $3(3 / 0)$ \\
Delayed oral phase (oral/NG tube), $n$ & $7(7 / 0)$ \\
GI bleeding (oral/NG tube), $n$ &
\end{tabular}

Table 2 shows the characteristics of the enrolled patients, including their neurological problems. In children with hypertonicity, 11 had a MAS score $\geq 2$, and 3 had a MAS score of 1 [18]. Sixteen patients underwent PEG tube insertion using the pull-through method, and one underwent insertion using the push-through method. The gastrostomy tube of one patient was re-inserted surgically, due to transverse colonic perforation after the pull-through method. Otherwise, no surgical complications were noted. The baseline laboratory test results were within normal limits (Supplementary Table S1).

Table 2. Neurological characteristics, according to disease entities of the enrolled patients.

\begin{tabular}{cc}
\hline Disease Entities & Number of Patients \\
\hline Spasticity & 14 \\
Hypoxic ischemic encephalopathy & 2 \\
Cerebral palsy & 4 \\
Schizencephaly & 1 \\
Alpert syndrome & 1 \\
Lennox-Gastaut syndrome & 3 \\
Devic syndrome & 2 \\
Lissencephaly & 1 \\
Hypotonicity & 4 \\
Cerebral palsy & 1 \\
Rett syndrome & 1 \\
Lennox-Gastaut syndrome & 1 \\
Spinal muscular dystrophy & 1 \\
\hline
\end{tabular}

\subsection{Changes in Anthropometric Data}

According to the BMI-for-age $z$-score of the 2017 Korea National Growth Chart [15], all 16 children aged $\geq 24$ months were wasted or severely wasted at the baseline visit. The proportion of severe malnourishment in children aged $\geq 24$ months decreased from $56.3 \%$ to $38.5 \%$ during the study period. One patient was obese by the time of the last visit (Figure 1). Two children aged $<24$ months were well-nourished according to the weight-for-height $z$-score, and they maintained their well-nourished status during the study period. 


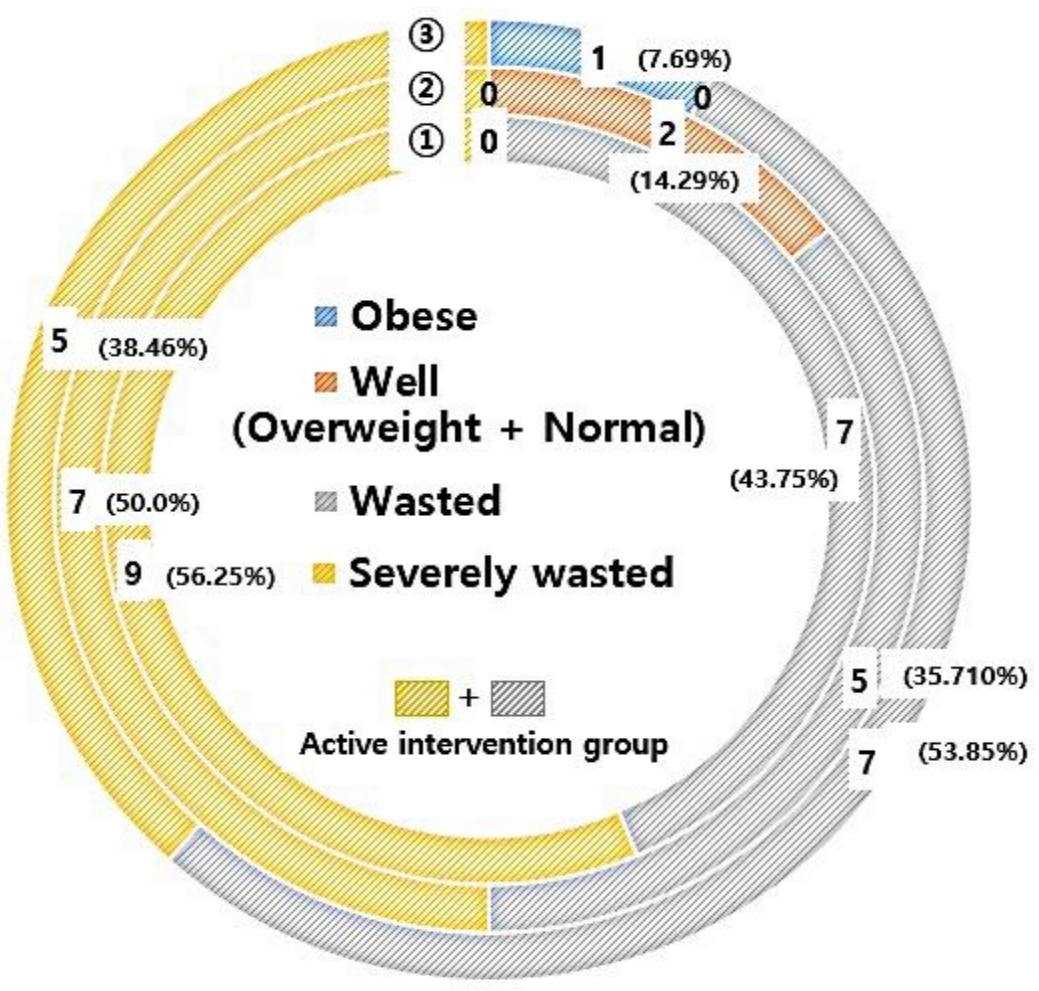

Figure 1. Nutritional evaluation during the study period according to body mass index-for-age $z$-score.

(1) baseline visit; (2) 6-month visit; (3) Last visit.

(95\% CI: 2.53-29.34, $p=0.009$ ), PIBW (95\% CI: 0.26-26.92, $p=0.041$ ), and height-for-age $z$-score (95\% CI: 0.00-1.67, $p=0.034$ ) improved significantly at the 6-month and last visits (Table 3). The other anthropometric parameter changes are shown in Table 3.

Table 3. Changes in the anthropometric parameters and nutrition during the study period.

\begin{tabular}{|c|c|c|c|c|c|c|}
\hline \multirow{2}{*}{ Measurement } & \multicolumn{3}{|c|}{ Median (IQR) } & \multicolumn{3}{|c|}{$p$-Values } \\
\hline & Baseline Visit & 6-Month Visit & Last Visit & $*$ & $* *$ & $* * *$ \\
\hline Height percentile ${ }^{\text {(a) }}$ & $59.3(41.04-80.47)$ & $55.06(33.7-76]$ & $53.48(33.6-83.69)$ & 0.061 & 0.308 & 0.3 \\
\hline Weight percentile & $37.83(9.96-62.23)$ & 41.39 (11.87-77.5] & $51.15(13.91-83.05)$ & 0.134 & 0.859 & 0.331 \\
\hline BMI percentile ${ }^{(a)}$ & $11.64(4.55-35.34)$ & $26.03(4.55-54.23]$ & $35.93(4.54-58.64)$ & 0.158 & 0.009 & 0.136 \\
\hline PIBW $^{(a)}$ & 81.41 (63.91-93.79) & $\begin{array}{c}90.44 \\
(68.68-103.77)\end{array}$ & $\begin{array}{c}90.41 \\
(69.09-108.68)\end{array}$ & 0.003 & 0.041 & 0.056 \\
\hline Height $z$-score ${ }^{(b)}$ & $\begin{array}{c}-2.88 \\
(-5.57-(-0.73))\end{array}$ & $\begin{array}{c}-3.25 \\
(-5.35-(-0.55))\end{array}$ & $\begin{array}{c}-2.62 \\
(-4.52-(-1.3))\end{array}$ & 0.255 & 0.034 & 0.158 \\
\hline Weight $z$-score ${ }^{(\mathrm{b})}$ & $\begin{array}{c}-3.85 \\
(-6.67-(-0.84))\end{array}$ & $-3.61(-6.21-0.6)$ & $\begin{array}{c}-2.77 \\
(-5.41-(-0.42))\end{array}$ & 0.011 & 0.136 & 0.975 \\
\hline BMI z-score ${ }^{(b)}$ & $\begin{array}{c}-3.29 \\
(-4.65-(-0.55))\end{array}$ & $-1.18(-4.41-0.46)$ & $-1.61(-4.48-0.72)$ & 0.005 & 1 & 0.158 \\
\hline CIR & $45.42(37.22-83.93)$ & $80(75-100)$ & 85.72 (79.45-95.32) & 0.015 & 0.953 & 0.016 \\
\hline PIR & $50.12(35.84-82.2)$ & $84(69-101.34)$ & $90(82.5-95.91)$ & 0.004 & 1 & 0.002 \\
\hline
\end{tabular}

$p$-values were determined using the Wilcoxon signed-rank test. ${ }^{*} p$-value for differences between the initial visit and the 6-month visit. ** $p$-value for differences between the 6-month visit and the last visit. ${ }^{* * *} p$-value for differences between the initial visit and the last visit. BMI: Body mass index, CIR: Calorie intake compared to the recommended requirement, IQR: Interquartile range, PIBW: Percent of ideal bodyweight, PIR: Protein intake compared to the recommended requirement. ${ }^{\text {(a) }}$ Percentile measured based on the growth curves for cerebral palsy according to sex and the Gross Motor Function Classification System level. ${ }^{(b)} z$-score calculated based on the 2017 Korea National Growth Chart data.

\subsection{Changes in Caloric and Protein Intake}

Both caloric and protein intake increased significantly after PEG tube insertion (Table 3 ). The calorie intake increased from $45.4 \%$ to $80.0 \%$ during the 6-month period (95\% CI: 6.21-44.23, $p=0.015$ compared 
to the recommended requirement (CIR)) and then to $85.7 \%$ at the last visit (95\% CI: $14.25-52.52, p=0.016$ ). The protein intake increased from $50.1 \%$ to $84.0 \%$ (95\% CI: $14.66-49.73, p=0.004$ compared to the recommended requirement (PIR)) at the 6-month visit and then to $90.0 \%$ (95\% CI: 24.09-55.73, $p=0.002$ ) at the last visit.

\subsection{Anthropometric Parameters and Nutritional Intake by Previous Feeding Method}

The anthropometric data and nutritional assessment data of the oral feeding and NG tube feeding groups were compared. The baseline BMI-for-age $z$-score, BMI-for-age percentile, and PIBW of the NG tube feeding group were significantly better than those of the oral feeding group ( $p=0.02$ for BMI $z$-score, $p=0.02$ for BMI percentile, and $p=0.03$ for PIBW) at baseline and 6-month visit. The median BMI $z$-score of the oral feeding group was -4.55 (IQR, -5.97 to -3.85 ), that of the BMI percentile was 4.64 (IQR, 4.41-5.05), and that of the PIBW was 65.19 (IQR, 49.99-80.2). The median BMI $z$-score of the NG tube feeding group was -1.13 (IQR, -3.2 to 0.28 ), that of the BMI percentile was 30.93 (IQR, 11.55-47.17), and that of the PIBW was 91.6 (IQR, 78.01-91.6) (Supplementary Table S2).

The baseline median CIR of the oral feeding group was 43.55 (IQR, 38.75-49.56), while that of the NG tube feeding group was 62.5 (IQR, 34.78-92.32). The baseline median PIR of the oral feeding group was 50.12 (IQR, 38.34-56.28), while that of the NG tube feeding group was 55.68 (IQR, 29.7-88.79). There were no significant differences in baseline nutrition between the two groups.

During the study period, the CIR and PIR of both groups improved (Figure 2, Supplementary Table S2). The oral feeding group showed greater improvement during the first six months $(95 \% \mathrm{CI}$ : 25.58-53.92, $p=0.01$ for CIR; 95\% CI: $15.67-70.01, p=0.02$ for PIR). The increase in nutritional intake in the oral feeding group was better than that in the NG tube feeding group (95\% CI: -22.79-47.39, $p=0.01$ for CIR; 95\% CI: -3.95-49.89) (Figure 2, Supplementary Table S2).

\subsection{Anthropometric Parameters and Nutritional Intake by Patient Muscle Tone}

We compared the parameters according to the patients' muscle tonicity (hypertonic vs. hypotonic). Figure 3 compares the anthropometric changes and nutritional intake changes between groups; detailed data are shown in Supplement Table S3. In the hypertonic group, the PIBW (during the first six months: 95\% CI: 2.14-16.42, $p=0.02$; during the study period: $95 \%$ CI: $-0.18-24.45, p=0.05$ ) and PIR (during the first six months: $95 \%$ CI: $12.33-56.00, p=0.01$; during the study period: $95 \%$ CI: $17.13-57.83, p=0.01$ ) were continuously improved during the study period. The BMI-for-age $z$-score of the hypertonic type group was also increased at the 6-month visit (95\% CI: 0.16-1.69, $p=0.03)$. There were statistically significant increases in BMI-for-age percentile (95\% CI: $-5.01-23.67, p=0.03)$, height-for-age $z$-score (95\% CI: $-1.76-0.2, p=0.05$ ), and CIR between the 6-month visit and the last visit (95\% CI: 10.42-57.14, $p=0.03$ ). In the hypotonic group, all anthropometric parameters, except height-for-age percentile and height-for-age $z$-score, and nutritional data improved without statistical significance. 
a) Height-for-age percentile Weight-for-age percentile BMI-for-age percentile

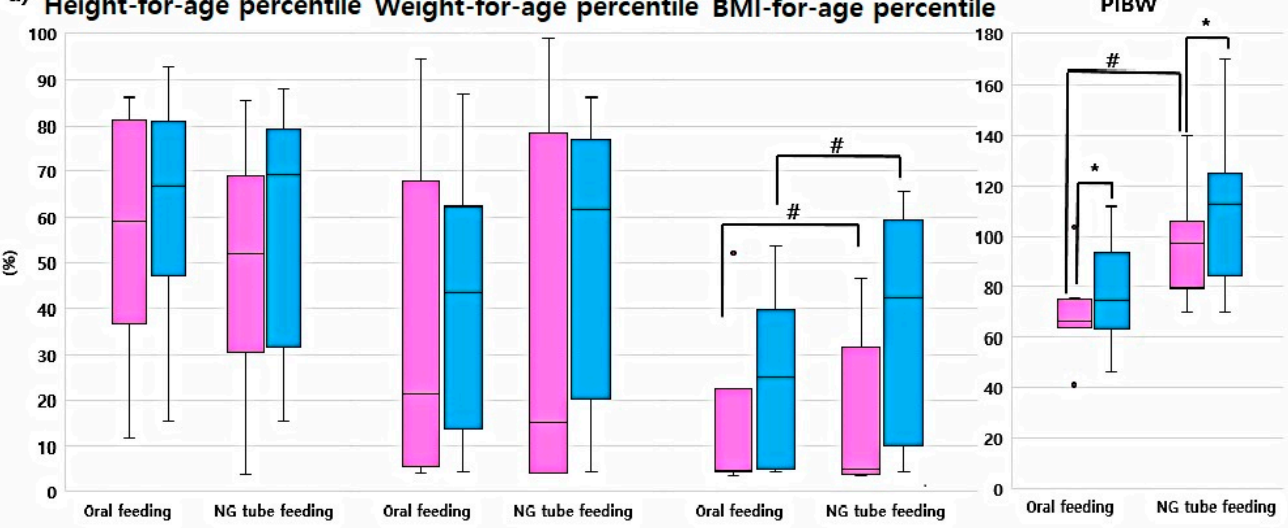

b) Height-for-age z-score Weight-for-age z-score BMI-for-age z-score

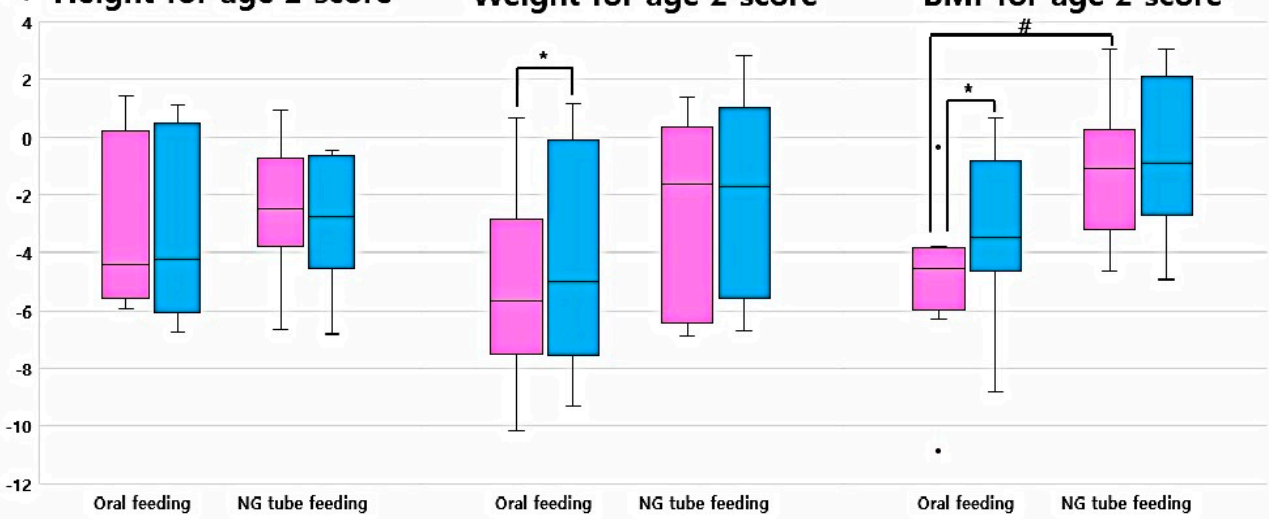

c) Ratio of Calorie intake to Requirement

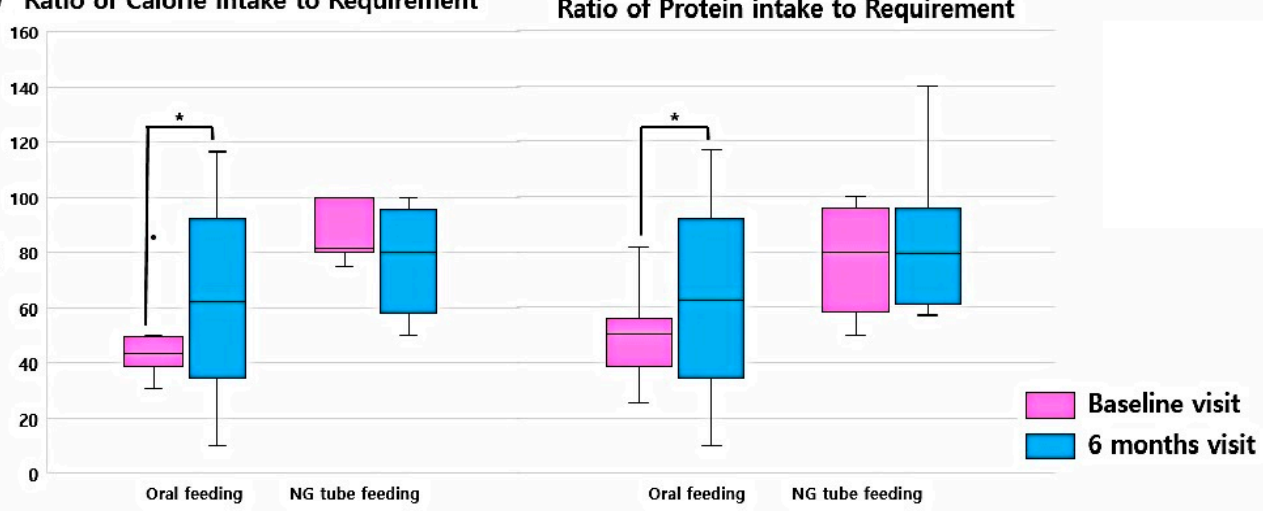

Figure 2. Comparisons of changes in anthropometric parameters and the ratio of nutritional intake between previous oral feeding group and NG tube feeding group. (a) Anthropometric parameters for-age percentile and percent ideal body weight. The percentile of each anthropometric parameter was calculated using the growth curve for cerebral palsy patients by Brooks et al. [16] and percent ideal body weight was calculated using the Moore method. (b) Anthropometric parameter for-age $z$-score. (c) Ratio of caloric intake to required amount and ratio of protein intake to required amount. NG tube feeding, fed via nasogastric tube before PEG tube insertion; oral feeding, fed orally before PEG tube insertion; PIBW, percent ideal body weight. ${ }^{*} p<0.05$ by Wilcoxon signed-rank test; \# $p<$ 0.05 by Mann-Whitney $U$ test. 


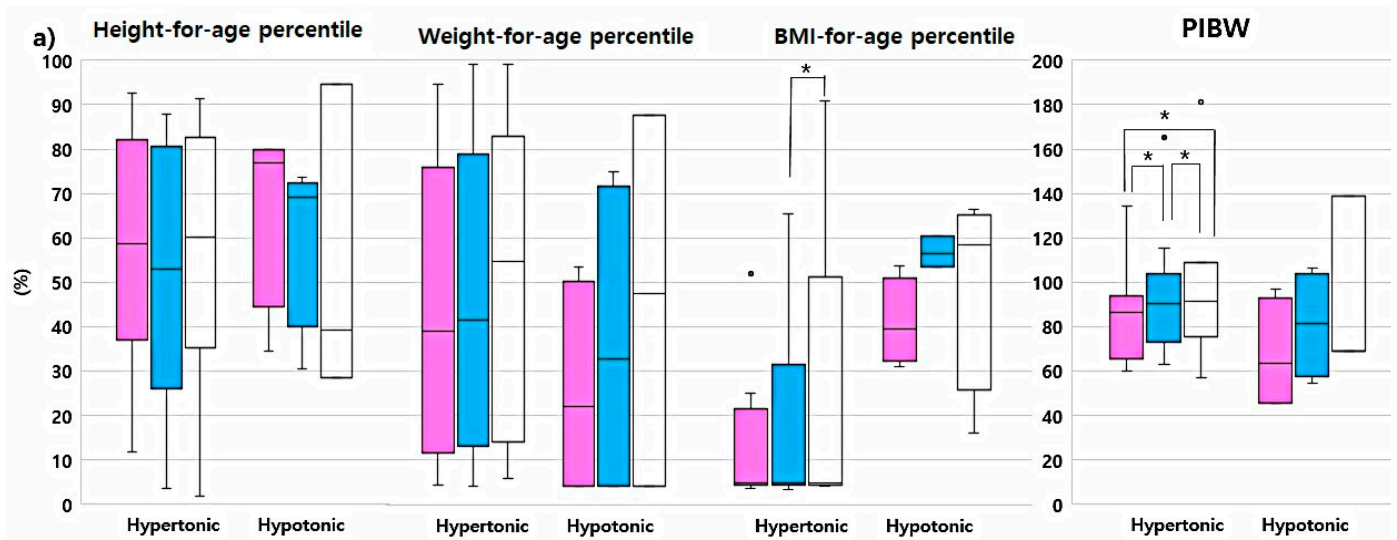

b) Height-for-age z-score

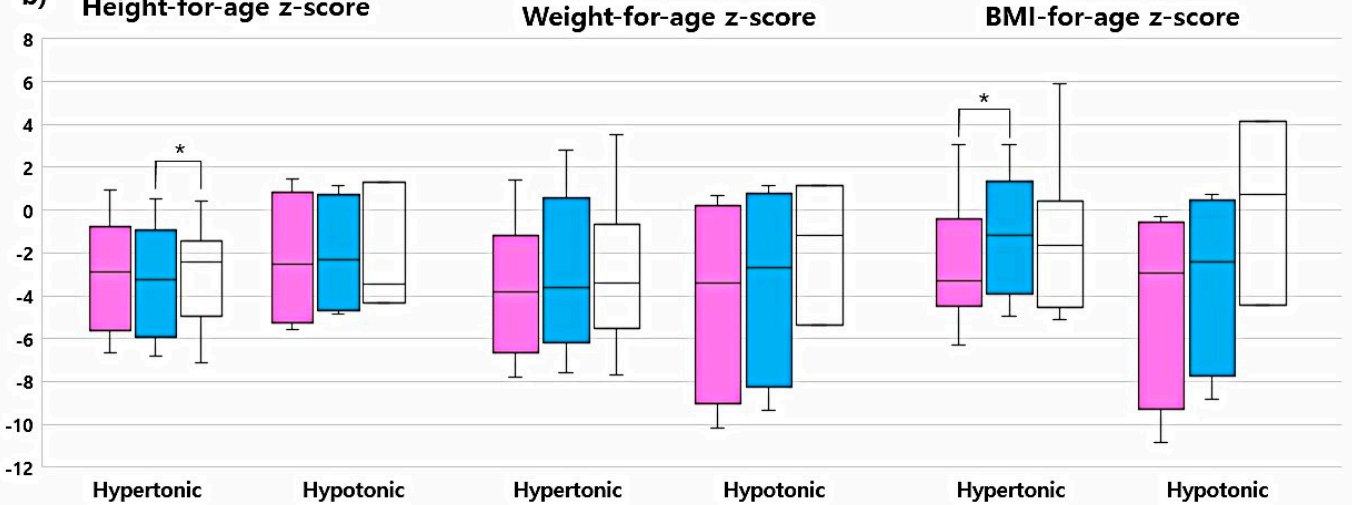

c) Ratio of Calorie Intake to Required amount Ratio of Protein Intake to Required amount

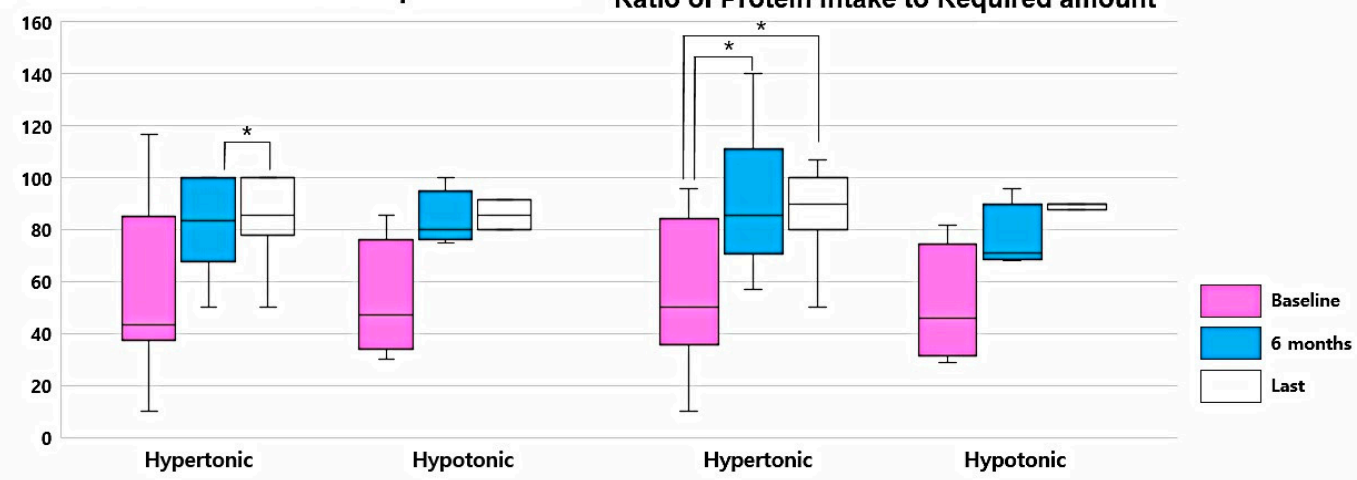

Figure 3. Comparisons of changes in anthropometric parameters and nutritional ratio between hypertonic and hypotonic groups. (a) Anthropometric parameters for-age percentile and percent ideal body weight. The percentile of each anthropometric parameter was calculated using the growth curve for cerebral palsy patients by Brooks and percent ideal body weight was calculated using Moore methods. (b) Anthropometric parameters for-age z-score. (c) Ratio of caloric intake to required amount and ratio of protein intake to required amount. NG tube feeding, fed via nasogastric tube before PEG tube insertion; oral feeding, fed orally before PEG tube insertion; PEG, percutaneous endoscopic gastrostomy; PIBW, percent ideal body weight. * $p$-value $<0.05$ by Wilcoxon signed-rank test.

\section{Discussion}

Nutritional support, including enteral feeding, helps solve the nutritional deficiencies of neurologically impaired children. The body composition parameters, including anthropometric variables, muscle mass, bone density, and fat deposition of these patients are reduced [24-26]; thus, special growth curves have been developed for patients with CP. Several studies have attempted to design growth charts for pediatric patients with CP at each GMFCS level $[16,27,28]$. However, these growth curves did not include children under two years of age. The ESPGHAN guideline 
recommends using the WHO growth chart in the anthropometric evaluation of children with neurological disabilities [29]. The 2017 Korean National Growth Charts were developed for normal and healthy children without any disabilities [15]. The ESPGHAN does not recommend that growth charts for patients with CP at each GMFCS level be used in the anthropometric and nutritional evaluation of pediatric neurologically impaired patients. However, there are no special growth curves for children with neurological diseases, and the growth of bedridden children is usually far from that of healthy children. Thus, along with applying the two standard growth curves for healthy children, we used the GMFCS curve to evaluate the degree of individual anthropometric and nutritional improvement in these patients.

IBW or optimal bodyweight [30] can be used to evaluate the degree of malnutrition. Waterlow defined malnutrition in pediatric patients using the PIBW calculation ((actual bodyweight/IBW) $\times 100$ ) [20]. There are several methods for calculating IBW, and the most common methods used in children are the McLaren method [31], the Moore method [17], and the BMI method [32]. We chose the Moore method, using the same weight and height percentiles. We calculated IBW and BMI with estimated height using ulnar length and used these anthropometric parameters to evaluate the degree of catch-up growth; this estimated height would likely magnify the possible error, due to the possible gap between actual height and calculated height.

A previous study reported that the anthropometric parameters of children with $\mathrm{CP}$ aged 5 months to 17 years were improved 6 and 12 months after PEG tube insertion without serious complications [33], while another study reported similar outcomes [34]. Most other previous studies focused on complications [11,35] or comparisons between PEG tube insertion techniques [10,36-40].

To the best of our knowledge, this is the first study with a follow-up period of longer than 12 months (6.5-year total study period) to evaluate the anthropometric and nutritional effects after PEG tube insertion. We found that children achieved most of the catch-up growth and nutritional correction in the six months following PEG tube insertion. Weight-for-age, BMI-for-age $z$-score, and PIBW were improved, and the PIBW reached almost $100 \%$ at the 6-month follow-up visit. However, the changes in anthropometric parameters were minimal after six months. This finding implies that most of the catch-up growth was achieved in the first six months; thus, we should focus on nutritional care during this period since it appears to be important for the overall outcomes. One child became obese after the intervention period; it can be assumed that this is because individualized nutrition guidelines for different disease entities have not yet been developed. Therefore, continuous nutritional support is important to maintain the patients' nutritional status.

The baseline BMI-for-age percentile, $z$-score, and PIBW of the NG tube feeding group were better than those of the oral feeding group. The oral feeding group increased caloric intake during the first six months after PEG tube insertion. Nutritional intake of the NG tube feeding group was increased without statistical significance; thus, we assume that children with NG tube feeding would not be affected by switching to a PEG tube. This result implies that PEG tube feeding is superior to NG tube feeding to provide stable nutritional support. Moreover, NG tube feeding can cause complications, such as gastrointestinal bleeding and aspiration. Indeed, seven of our 10 patients with NG tubes experienced bleeding ulcers, while the remaining three had aspiration problems prior to PEG insertion. We can assume that these complications prevented their caregivers from actively feeding the patients.

An Asian cultural background makes parents reluctant to subject their children to invasive procedures, such as NG tube placement, and a considerable number of parents in our study had refused PEG tube insertion for a long time. This repulsive emotion has a tendency to worsen malnutrition and delay the treatment of the underlying disease. In our study, two children under 24 months were maintained a normal or overweight status; this may be due to the short duration of diseases and earlier intervention and suggests that earlier nutritional intervention can prevent malnutrition. Considering previous studies demonstrating the improved quality of life of caregivers [41-43] and better prognosis with earlier interventions [34], clinicians should encourage caregivers to consider allowing PEG tube insertion earlier to better support their children's health. 
Another interesting result was that the BMI for-age $z$-score and PIBW in the hypertonic group improved significantly after PEG tube insertion, but did not improve in the hypotonic group despite similar increases in nutritional intake. Since the number of hypotonic children was small, we could not demonstrate statistical significance. To the best of our knowledge, this is the first study to show different nutritional improvement according to the muscle tonicity after PEG tube feeding. A previous study on hemiplegic $\mathrm{CP}$ of asymmetric growth between the affected and unaffected sides [44] reported that $\mathrm{CP}$ patients have different growth patterns and require different nutritional support depending on the CP type. Another study revealed that hypertonic children had lower fat mass, fat free mass, and total bodyweight [45]. Hypertonic children often experience swallowing difficulty, due to the increased muscle tone [46], making feeding difficult in these children. Thus, we assume that the actual effective nutritional volume is smaller than the total feeding volume. The actual effective nutritional volume may have been increased after PEG tube insertion; this seems to be an important reason for the anthropometric and nutritional improvement observed in hypertonic children. However, an extended study with a larger study population is warranted to fully validate this finding.

In comparison with that after the nutritional evaluation using growth curves for $\mathrm{CP}$, the poor nutritional status was overly exaggerated when our patients were assessed against the 2017 Korea National Growth Charts $[15,16]$, which explains the universal validation of CP growth curves. Moreover, there are no standardized growth curves or equations of nutrition tailored to the degree of rigidity.

The laboratory findings did not provide significant nutritional information during the study period, which demonstrated that the assessment of macronutrients using laboratory tests would not support the nutritional status of children with neurologic impairments. The ESPGHAN recommends micronutrient assessment (calcium; iron; zinc; vitamins C, D, and E; and selenium) [29]. Vitamin D is important in bone metabolism, and its deficiency is a high risk of fractures [25], while zinc is reported to be important for the prevention of seizures [47]. Children with epilepsy have been reported to have lower levels of zinc [48], while children with neurological impairments have lower levels of vitamin $\mathrm{D}$ [49]. Since these micronutrients are crucial for the good prognosis of patients, it is important to regularly test micronutrients and give the patients a sufficient dietary intake. In this study, vitamin D was checked routinely according to the recommendation of the PNST; the vitamin D levels were not particularly low and did not change significantly during the study. There were insufficient data on zinc levels to analyze. The provision of a sufficient amount of micronutrients according to the micronutrient level in regular follow-up will help to improve the nutrition of these children.

This study had several limitations. It was a retrospective study with a small number of patients. In the future, a large-scale study, including more detailed micronutrient data (such as vitamin C, zinc, and iron, and anthropometric parameters, e.g., fat mass, fat free mass, and bone mineral density), are needed to fully validate our findings.

\section{Conclusions}

When a child's nutritional intake is insufficient, PEG tube insertion should be actively encouraged to ensure adequate nutritional support, even if he or she can eat orally. This must be explained to caregivers and physicians alike. Regular intervention by the PNST is important to ensure adequate nutritional support for children. In the future, the development of a growth chart for neurologically impaired children according to the degree of rigidity is required to ensure adequate nutritional support for this population. The findings of the current study might contribute to establishing individualized nutritional plans for children with neurological disabilities.

Supplementary Materials: The following are available online at http://www.mdpi.com/2077-0383/9/10/3295/s1: Table S1: Laboratory findings during the study period, Table S2: Comparisons of the anthropometric and nutritional parameters between the previous oral feeding group and the NG tube feeding group during the study period. Table S3: Comparisons of the anthropometric and nutritional parameters between the hypertonic and hypotonic groups during the study period. 
Author Contributions: Conceptualization, methodology and formal analysis C.-r.S. and J.O.S.; data duration and investigation, C.-r.S., W.K., B.-L.E. and J.O.S.; writing-original draft, C.-r.S.; Writing-review and editing and supervision, J.O.S.; All authors have read and agreed to the published version of the manuscript.

Funding: This study was supported by Korea University Hospital Hin Moe (Hyun-Gum Lee) Research Fund.

Acknowledgments: We thank the members of the pediatric nutritional support team and all attending physicians for their assistance with this study.

Conflicts of Interest: The authors declare no conflict of interest.

Data Statement: Data sharing is unavailable due to limited IRB approval.

\section{Abbreviations}

$\begin{array}{ll}\text { PEG } & \text { Percutaneous endoscopic gastrostomy } \\ \text { PNST } & \text { Pediatric nutritional support team } \\ \text { NG } & \text { Nasogastric } \\ \text { EGD } & \text { Esophagogastroduodenoscopy } \\ \text { CP } & \text { Cerebral palsy } \\ \text { GMFCS } & \text { Gross Motor Function Classification System } \\ \text { PIBW } & \text { Percent of ideal bodyweight } \\ \text { IQR } & \text { Interquartile range } \\ \text { CI } & \text { Confidence interval } \\ \text { CIR } & \text { Calorie intake compared to the recommended requirement } \\ \text { PIR } & \text { Protein intake compared to the recommended requirement }\end{array}$

\section{References}

1. Sullivan, P. Nutrition and growth in children with cerebral palsy: Setting the scene. Eur. J. Clin. Nutr. 2013, 67, S3-S4. [CrossRef]

2. Kuperminc, M.; Gottrand, F.; Samson-Fang, L.; Arvedson, J.; Bell, K.; Craig, G.; Sullivan, P. Nutritional management of children with cerebral palsy: A practical guide. Eur. J. Clin. Nutr. 2013, 67, S21-S23. [CrossRef]

3. Sullivan, P.; Lambert, B.; Rose, M.; Ford-Adams, M.; Johnson, A.; Griffiths, P. Prevalence and severity of feeding and nutritional problems in children with neurological impairment: Oxford feeding study. Dev. Med. Child Neurol. 2000, 42, 674-680. [CrossRef]

4. Trier, E.; Thomas, A.G. Feeding the disabled child. Nutrition 1998, 14, 801-805. [CrossRef]

5. Penagini, F.; Mameli, C.; Fabiano, V.; Brunetti, D.; Dilillo, D.; Zuccotti, G.V. Dietary intakes and nutritional issues in neurologically impaired children. Nutrients 2015, 7, 9400-9415. [CrossRef]

6. Shapiro, B.K.; Green, P.; Krick, J.; Allen, D.; Capute, A.J. Growth of severely impaired children: Neurological versus nutritional factors. Dev. Med. Child Neurol. 1986, 28, 729-733. [CrossRef]

7. Bell, K.L.; Boyd, R.N.; Tweedy, S.M.; Weir, K.A.; Stevenson, R.D.; Davies, P.S. A prospective, longitudinal study of growth, nutrition and sedentary behaviour in young children with cerebral palsy. BMC Public Health 2010, 10, 179. [CrossRef] [PubMed]

8. Patrick, J.; Boland, M.; Stoski, D.; Murray, G.E. Rapid correction of wasting in children with cerebral palsy. Dev. Med. Child Neurol. 1986, 28, 734-739. [CrossRef]

9. Stallings, V.A.; Cronk, C.E.; Zemel, B.S.; Charney, E.B. Body composition in children with spastic quadriplegic cerebral palsy. J. Pediatrics 1995, 126, 833-839. [CrossRef]

10. Vervloessem, D.; van Leersum, F.; Boer, D.; Hop, W.C.; Escher, J.C.; Madern, G.C.; de Ridder, L.; Bax, K.N. Percutaneous endoscopic gastrostomy (PEG) in children is not a minor procedure: Risk factors for major complications. Semin. Pediatric Surg. 2009, 18, 93-97. [CrossRef]

11. Fernandes, A.R.; Elliott, T.; McInnis, C.; Easterbrook, B.; Walton, J.M. Evaluating complication rates and outcomes among infants less than $5 \mathrm{~kg}$ undergoing traditional percutaneous endoscopic gastrostomy insertion: A retrospective chart review. J. Pediatric Surg. 2018, 53, 933-936. [CrossRef] [PubMed]

12. Sullivan, P.B. Pros and cons of gastrostomy feeding in children with cerebral palsy. Paediatr. Child Health 2014, 24, 351-354. [CrossRef] 
13. Burdall, O.C.; Howarth, L.J.; Sharrard, A.; Lee, A.C. Paediatric enteral tube feeding. Paediatr. Child Health 2017, 27, 371-377. [CrossRef]

14. Gauld, L.M.; Kappers, J.; Carlin, J.B.; Robertson, C.F. Height prediction from ulna length. Dev. Med. Child Neurol. 2004, 46, 475-480. [CrossRef]

15. Kim, J.H.; Yun, S.; Hwang, S.-S.; Shim, J.O.; Chae, H.W.; Lee, Y.J.; Lee, J.H.; Kim, S.C.; Lim, D.; Yang, S.W. The 2017 Korean National Growth Charts for children and adolescents: Development, improvement, and prospects. Korean J. Pediatrics 2018, 61, 135. [CrossRef] [PubMed]

16. Brooks, J.; Day, S.; Shavelle, R.; Strauss, D. Low weight, morbidity, and mortality in children with cerebral palsy: New clinical growth charts. Pediatrics 2011, 128, e299-e307. [CrossRef]

17. Moore, D.; Durie, P.; Forstner, G.; Pencharz, P. The assessment of nutritional status in children. Nutr. Res. 1985, 5, 797-799. [CrossRef]

18. Rw, B.; Smith, M. Interrater reliability of a modified Ashworth scale of muscle spasticity. Phys. Ther. 1987, 67, 206-207.

19. WHO. Child Growth Standards: Training Course on Child Growth Assessment; WHO: Geneva, Switzerland, 2008.

20. Waterlow, J. Classification and definition of protein-calorie malnutrition. Br. Med, J. 1972, 3, 566. [CrossRef]

21. Centers for Disease Control and Prevention. About Child \& Teen BMI.; CDC: Atlanta, GA, USA, 2015.

22. Schofield, W. Predicting basal metabolic rate, new standards and review of previous work. Human Nutr. Clin. Nutr. 1985, 39, 5-41.

23. Schlenker, E.; Roth, S.L. Williams' Essentials of Nutrition and Diet Therapy-Revised Reprint-E-Book; Elsevier Health Sciences: Amsterdam, The Netherlands, 2013.

24. Henderson, R.C.; Lark, R.K.; Gurka, M.J.; Worley, G.; Fung, E.B.; Conaway, M.; Stallings, V.A.; Stevenson, R.D. Bone density and metabolism in children and adolescents with moderate to severe cerebral palsy. Pediatrics 2002, 110, e5. [CrossRef] [PubMed]

25. Fung, E.B.; Samson-Fang, L.; Stallings, V.A.; Conaway, M.; Liptak, G.; Henderson, R.C.; Worley, G.; O'Donnell, M.; Calvert, R.; Rosenbaum, P. Feeding dysfunction is associated with poor growth and health status in children with cerebral palsy. J. Am. Diet. Assoc. 2002, 102, 361-373. [CrossRef]

26. Zainah, S.; Ong, L.; Sofiah, A.; Poh, B.K.; Hussain, I. Determinants of linear growth in Malaysian children with cerebral palsy. J. Paediatr. Child Health 2001, 37, 376-381. [CrossRef]

27. Day, S.M.; Strauss, D.J.; Vachon, P.J.; Rosenbloom, L.; Shavelle, R.M.; Wu, Y.W. Growth patterns in a population of children and adolescents with cerebral palsy. Dev. Med. Child Neurol. 2007, 49, 167-171. [CrossRef]

28. Stevenson, R.D.; Conaway, M.; Chumlea, W.C.; Rosenbaum, P.; Fung, E.B.; Henderson, R.C.; Worley, G.; Liptak, G.; O'Donnell, M.; Samson-Fang, L. Growth and health in children with moderate-to-severe cerebral palsy. Pediatrics 2006, 118, 1010-1018. [CrossRef]

29. Romano, C.; Van Wynckel, M.; Hulst, J.; Broekaert, I.; Bronsky, J.; Dall'Oglio, L.; Mis, N.F.; Hojsak, I.; Orel, R.; Papadopoulou, A. European society for paediatric gastroenterology, hepatology and nutrition guidelines for the evaluation and treatment of gastrointestinal and nutritional complications in children with neurological impairment. J. Pediatric Gastroenterol. Nutr. 2017, 65, 242-264. [CrossRef]

30. Phillips, S.; Edlbeck, A.; Kirby, M.; Goday, P. Ideal body weight in children. Nutr. Clin. Pract. 2007, 22, 240-245. [CrossRef]

31. Mclaren, D.; Read, W.C. Classification of nutritional status in early childhood. Lancet 1972, 300, $146-148$. [CrossRef]

32. Ringwald-Smith, K.; Cartwright, C.; Mosby, T. Medical nutrition therapy in pediatric oncology. In The Clinical Guide to Oncology Nutrition, 2nd ed.; American Dietetics Association: Cleveland, OH, USA, 2006; pp. 110-125.

33. Sullivan, P.B.; Juszczak, E.; Bachlet, A.M.; Lambert, B.; Vernon-Roberts, A.; Grant, H.W.; Eltumi, M.; McLean, L.; Alder, N.; Thomas, A.G. Gastrostomy tube feeding in children with cerebral palsy: A prospective, longitudinal study. Dev. Med. Child Neurol. 2005, 47, 77-85. [CrossRef]

34. Martínez-Costa, C.; Calderón, C.; Gómez-López, L.; Borraz, S.; Crehuá-Gaudiza, E.; Pedrón-Giner, C. Nutritional outcome in home gastrostomy-fed children with chronic diseases. Nutrients 2019, 11, 956. [CrossRef] [PubMed]

35. Dipasquale, V.; Catena, M.A.; Cardile, S.; Romano, C. Standard polymeric formula tube feeding in neurologically impaired children: A five-year retrospective study. Nutrients 2018, 10, 684. [CrossRef] [PubMed] 
36. Akay, B.; Capizzani, T.R.; Lee, A.M.; Drongowski, R.A.; Geiger, J.D.; Hirschl, R.B.; Mychaliska, G.B. Gastrostomy tube placement in infants and children: Is there a preferred technique? J. Pediatric Surg. 2010, 45, 1147-1152. [CrossRef] [PubMed]

37. Wragg, R.C.; Salminen, H.; Pachl, M.; Singh, M.; Lander, A.; Jester, I.; Parikh, D.; Jawaheer, G. Gastrostomy insertion in the 21st century: PEG or laparoscopic? Report from a large single-centre series. Pediatric Surg. Int. 2012, 28, 443-448. [CrossRef] [PubMed]

38. Baker, L.; Beres, A.L.; Baird, R. A systematic review and meta-analysis of gastrostomy insertion techniques in children. J. Pediatric Surg. 2015, 50, 718-725. [CrossRef]

39. Minar, P.; Garland, J.; Martinez, A.; Werlin, S. Safety of percutaneous endoscopic gastrostomy in medically complicated infants. J. Pediatric Gastroenterol. Nutr. 2011, 53, 293-295. [CrossRef]

40. Rahnemai-Azar, A.A.; Rahnemaiazar, A.A.; Naghshizadian, R.; Kurtz, A.; Farkas, D.T. Percutaneous endoscopic gastrostomy: Indications, technique, complications and management. World J. Gastroenterol. 2014, 20, 7739. [CrossRef]

41. Sullivan, P.B.; Juszczak, E.; Bachlet, A.M.; Thomas, A.G.; Lambert, B.; Vernon-Roberts, A.; Grant, H.W.; Eltumi, M.; Alder, N.; Jenkinson, C. Impact of gastrostomy tube feeding on the quality of life of carers of children with cerebral palsy. Dev. Med. Child Neurol. 2004, 46, 796-800. [CrossRef]

42. Brotherton, A.M.; Abbott, J.; Aggett, P.J. The impact of percutaneous endoscopic gastrostomy feeding in children; the parental perspective. Child Care Health Dev. 2007, 33, 539-546. [CrossRef]

43. Martínez-Costa, C.; Calderón, C.; Gómez-López, L.; Borraz, S.; Pedrón-Giner, C. Satisfaction with gastrostomy feeding in caregivers of children with home enteral nutrition; application of the SAGA-8 questionnaire and analysis of involved factors. Nutr. Hosp. 2013, 28, 1121-1128.

44. Stevenson, R.D.; Roberts, C.D.; Vogtle, L. The effects of non-nutritional factors on growth in cerebral palsy. Dev. Med. Child Neurol. 1995, 37, 124-130. [CrossRef]

45. Więch, P.; Ćwirlej-Sozańska, A.; Wiśniowska-Szurlej, A.; Kilian, J.; Lenart-Domka, E.; Bejer, A.; Domka-Jopek, E.; Sozański, B.; Korczowski, B. The relationship between body composition and muscle tone in children with cerebral palsy: A case-control study. Nutrients 2020, 12, 864. [CrossRef] [PubMed]

46. Jesus, A.O.; Stevenson, R.D. Optimizing Nutrition and Bone Health in Children with Cerebral Palsy. Phys. Med. Rehabil. Clin. 2020, 31, 25-37. [CrossRef] [PubMed]

47. Sterman, M.B.; Shouse, M.N.; Fairchild, M.D. 1988 Zinc and seizure mechanisms. In Nutritional Modulation of Neural Function; Morley, J.E., Sterman, M.B., Walsh, J.H., Eds.; Academic Press: Cambridge, MA, USA, 1998; pp. 307-319.

48. Ganesh, R.; Janakiraman, L. Serum zinc levels in children with simple febrile seizure. Clin. Pediatr. 2008, 47, 164-166. [CrossRef] [PubMed]

49. Seth, A.; Aneja, S.; Singh, R.; Majumdar, R.; Sharma, N.; Gopinath, M. Effect of impaired ambulation and anti-epileptic drug intake on vitamin D status of children with cerebral palsy. Paediatr. Int. Child Health. 2017, 37, 193-198. [CrossRef] [PubMed]

Publisher's Note: MDPI stays neutral with regard to jurisdictional claims in published maps and institutional affiliations.

(C) 2020 by the authors. Licensee MDPI, Basel, Switzerland. This article is an open access article distributed under the terms and conditions of the Creative Commons Attribution (CC BY) license (http://creativecommons.org/licenses/by/4.0/). 